UDC: 161.1

\title{
New Remarks on the Concept in Logical Use
}

\author{
Nijaz Ibrulj 1
}

\begin{abstract}
The main thesis of this paper is directed against the traditional (cognitivetheoretical) definition of the concept which claims that the concept is the " thought about the essence of the object being thought", i.e. that it is "a set of essential features or essential characteristics of an object". But the " set of essential features or essential characteristics of an object of thought" is a " content" of the thought. The thought about the essence of an object is definition and the concept is not definition but the part of definition! Besides as the part of formal structure of thought, the concept possesses calculative logical properties that in formal logic (be it syllogistics, or the logic of propositions, or the logic of predicates) come to the front place of formal logical computation. Without the calculative properties of the concept, there would be no calculative properties of propositions which express the thought (thought structures). The calculative properties of a concept include the (1) degree of its logical generality (degree of variability), the (2) logical relations it can establish within the whole of the conceptual content, the (3) operability of the concept in structure of affirmation and negation, the (4) deducibility of either axiomatic or probabilistic systems. Therefore, I believe that, from the logical point of view, the definition of a concept should be applied in favor of its calculative properties that it possesses.
\end{abstract}

Key words: logic, concept, syllogistics, symbolic logic, truth value

\footnotetext{
${ }^{1}$ N.Ibrulj

University of Sarajevo, Faculty of Philosophy, Dept.of Philosophy

Franje Račkog 1, 71000 Sarajevo, Bosnia and Herzegovina

nijaz.ibrulj@ff.unsa.ba
} 


\section{Introduction}

Formal logic in its historical (traditional, theoretical) forms and modern applications (developmental, practical) is the most important part of Logical Science that makes logic an autonomous philosophical and scientific discipline that has its principles, its vocabulary and its field of research and is independent of philosophical disciplines (cognitive theory, epistemology, analytical philosophy), i.e. from philosophical (ontological) and scientific (epistemological) systems such as transcendental logic, speculative logic, hermeneutic logic or phenomenological logic.

Ancient formal logic (Aristotle's syllogistics) and modern formal logic (symbolic and mathematical logic) differ in the (1) type of language in which they express their forms and operations, in the (2) type of logical operations or logical calculus, in the (3) type of axiomatization and degree of formalization of logical deduction, and in the (4) type of derivation rules from axiomatic statement. Ancient formal logic is a partially formalized system of inference, while modern formal logic is a fully formalized system of inference and proof.

Logical ability or capacity for logical thinking, reasoning and proving, has always been valued and considered important both in practical work in decision making and problem solving and in the most complex philosophical constructions of systems and scientific theories, especially today marked by logical programming, artificial languages in application and artificial intelligence. But this enormous power (ability, skill) attributed to logical skill is in great disproportion to the very simple and few instruments behind that force: there are very few fundamental logical laws and rules that need to be mastered in order to arrive at a valid logical conclusion and valid logical proof.

The curiosity is that there are many times more logical errors (Bennett, 2012) in the formulation and explication of concepts, i.e. in the formulation of evidence of argumentation, than the number of laws and rules that need to be adopted according to the convention for formally correct inference and proof. The reason for this is that not all logical errors depend on errors in the logical construction, but also in the construction of the linguistic expression of argumentation, as well as in the intentional formulation of deceptive constructions of argumentation.

This logical minimalism in terms of conventional "logical tools" is justified by the simplicity of logical operations treated as intellectual operations of our mind (Boole, 1854:6), inclusion and exclusion of elements from the class of elements, 
subordination of concepts under the concepts and subsumption of objects under the concepts (Frege in Patzüg, 2008: 49) respect for logical laws and the application of several logical rules, as well as respect for the properties that logical relations have.

Logical ability is most often associated with and compared with mathematical ability, both in geometry and in algebra, i.e. arithmetic. Numerous logical operations are based on operations of general algebra or operations with sets and classes, i.e. with functions. Mathematical language is considered to be the clearest and most precise language of the hidden processes of the physical world and the forces acting in its forms. With mathematical language it is possible to create models of worlds that are not sensory observable and for whose possibility of existence there is a mathematical description as evidence. Mathematical language, however, is a consequence of the simplicity and clarity of the logical matrix on which every mathematical construction rests, although in fact the "logical matrix is the matrix that does not contain constants" but only variables! The clarity of the logical matrix actually lies in its generalization. (Whitehead and Russell, 1997: xxxi). On the other hand, all mathematics can be derived from a small number of logical laws and rules (Russell, 1996). And here we are again at the beginning: logic should be transparent, uncomplicated, clear and precise, a very simple basis from which primitive concepts (axioms) can construct incredibly complex thought constructions.

In that sense, logic acts as a simple grammar of a simple language that has a limited and finite vocabulary and a fund of terms with which an infinite number of linguistic constructions can be made! Logic here would be a deep grammar of the mind which works or should work in all vocabularies (logical, descriptive, deontic) giving them a normativity that can be "algorithmically decomposed" (Brandom, 2008: xvii). The real turn in logic came about by the complete formalization of logic made possible by "logical grammar", which threw "linguistic grammar" out of the game, and in which the key categories are: the "sentence", the "term", and the "functor" (Anderson and Belnap, 1990 : 474). As such, logic is an axiomatized and formalized deduction of conclusions and proofs from previously set premises or theses, and it does not allow for naive metaphysical constructions and logically impossible constructions either in thought or in language.

The logic of natural language and semantic constructions, and the logical syntax of expressions in natural language, are completely different from the logic of pure language, i.e. a sign language (L.Wittgenstein, in Tractatus: Zeichensprache) or a 
language of concepts (Frege, Begriffsschrift), which is made according to the paradigm of arithmetic language.

The difference is that the predication of species / genus properties to objects in syllogistics is based on the categorical schematism of concepts (terms) of different logical generality, while the determination of objects by properties by belonging to sets of objects in symbolic / mathematical logic is a type of combinatorial deduction (analysis), a relation of arguments (variables) and predicative parts (functions) via quantifiers and logical operators. However, logic that includes both natural language logic and sign language logic originated on the basis of the capacity of representation and identification of statements in natural language and representation and identification of statements in symbolic language, so that formal logic includes both options and translation of logical structures from formulation in natural language into the logical canonical notation of symbolic language, and vice versa.

In this article I want to introduce a new approach in understanding the basic logical form called "the concept" and which must be defined quite differently within the logical models of syntactic, semantic and pragmatic characterizations of its use. But the notion of truth and meaning in these two concepts of formal logic are completely different!

\section{The Concept in Traditional Logic: Cognitive-Theoretical Approach}

The traditional definition of the concept claims that the concept is "the thought about the essence of the object being thought", i.e. that it is "a set of essential features or essential characteristics of an object". But this definition of the concept needs to be checked!

For example, the concept of "Tiger" would be "a thought about the essence of a tiger." However, the word "Tiger" which expresses the concept "Tiger" does not indicate whether it is an animal species or a type of car tire or some glue or the name of a military or paramilitary unit or a German model of a heavy tank!

Likewise, the "concept of WATER" or the "concept of KWATER" (I will use here a thought experiment called Twin Earth by H. Putnam from his texts Meaning and Reference, 1973 and The Meaning of Meaning, 1975) expressed by the terms "WATER" and "KWATER" would immediately express the idea of the essence of a WATER object and a KWATER object! The word "Triangle" could also mean "the thought of the essential properties of a geometric figure with three angles", but also 
the thought of the relationship of three persons standing in the relationship of the "marriage triangle"!

In doing so, this definition of the concept does not take into account that the concept is a compress of logical generality and that the "essential characteristics of the object of thought" are in fact a network of concepts that stands in the predicative part of the definition of the object. As Gottlob Frege said (Über Begriff und Gegenstand) the concept (Begriff) is always a predicate (Frege, G. In Patzüg, G., 2008:48) and it is always necessary to either granulate (particulate) or homologize or unify (generalize) using quantifiers.

On the other hand, the object or object of thought is a compress of ontological generalities that is discriminated against in its understanding and expression from its universality by the use of space-time and terminological indexers.

The fact that a concept itself can be an object of thought, just as a word or expression of an object of language can be the subject of description in a metalanguage, suggests that a concept, object and word form a compress of logical, ontological and linguistic generalities. It is not possible to define each separately, but only in the stated triangulation and interaction.

Traditional theories of the concept (psychological, vulgar-materialistic, .. and the above realistic) start from the divided existence of objects, concepts and terms.

It is a trivial fact that the object, concept and linguistic expression (term) differ as elements of space-time, intellectual and linguistic area.

But neither in knowledge as a theoretical description of an object nor in the language in which that description is given nor in a thought content that fills both knowledge and language is there anything singular from the moment the cognitive process begins.

Theoretical knowledge is a relationship of logical, ontological and linguistic generalities that establish a hierarchy of mutual relations and the laws under which these relations can be made non-contradictory.

Every thought is a cognitive and logical creation of some definite or definable level of logical generality which is expressed by a simple or complex term or symbol.

Every concept is a part of a thought, simple or complex, but not every concept is a thought about the essence or essential properties of what is thought. 
In order for a term to be a thought about the essence of what is meant, it must possess the highest degree of logical generality (generic provision) attributed to the object defined by that term.

A thought can express an observation (so-called statements of observation or observation) or a belief or idea, but this does not mean that this thought is an expression of the essence or essential properties of an object, property or relation that is perceived, about which the idea is created or to which a belief has been formed.

Only when it forms part of the definition of the object of thought is the concept part of the thought of the essence of what is thought. Otherwise it seems a mistake to understand the concept as a definition and the concept as a sentence!

Some concepts are the parts of thought about essence or a thought about the essential characteristics of what is thought, but some concepts are not. The word taken for itself without connection with other words and without connection with the verb to be is not a concept. According to Aristotle, words that are expressed without any connection like "run", "win", "sit" are not a thought about the essence or essential properties of running, winning or sitting.

These words denote or express some state or action or the existence of some fact or some process. Only when "running" is defined as "a kind of movement of a living organism in space" can it be said that the concept or predicative part "a kind of movement of a living organism in space" at this stage determines the thought of the essence of running.

Further granulation of motion in space shows that behind one concept stands a network of concepts at different levels of logical generality.

Therefore, it can be said that the concept is a network or compress of the logical generality that at its universal level reaches the highest genus and at its singular level reaches the concept of perception and expression of the perception of an individual object.

\section{The Concept in Modern Logic: a Calculable Logical Entity}

According to the traditional understanding, the concept is the "thought of the essence of what we think"; or the "thought about the essence of the object of thought "; or the "thought of the essential characteristics of the object we think of." So: the thought we think by thought. For example: the concept "Logic" is a thought about the essential characteristics of logic. 
However, already with Aristotle (Posterior Analytics, II 89 b 23 ) there is a clear distinction between objects of scientifical knowledge based on the kinds of question

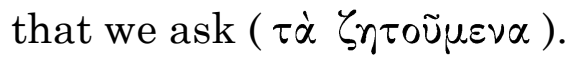

(1) a something (a fact: $\tau \dot{o}$ ó $\tau \iota)$ or the question of fact

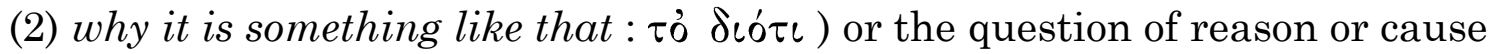

(3) that something is or is not: $\varepsilon \dot{i} \varepsilon \dot{\sigma} \tau \iota \nu)$ or the question of existence

(4) what something is ( $\tau \dot{\imath} \varepsilon \dot{\varepsilon} \sigma \iota \nu$ ) or the question of essence

And here we should add what Porphyrious noticed in terms: how we use a term in

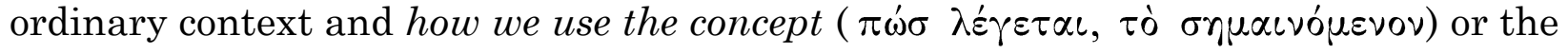
question of meaning (Porphyrious, Isagoge 2.5 -2.6, 2008,)

A word or a term that refers to something and names it as something that exists does not give a definition of it at the same time, i.e. it does not immediately denote its concept or thought about the essence of what they name.

That is why the word "Logic" does not give a definition or concept or thought about the essence of what logic is!

But can we have a concept of what we do not know if it exists and what it is if exists at all? For example, the term KWATER is a thought about the essence of the object KWATER (which we think by thought). In order to have the concept KWATER, we must define the object / substance / object / entity KWATER, i.e. say (1) whether or not there is an object / substance / object / entity marked with the name KWATER and (2) give a definition (object / substance / object / entity) KWATER, i.e. state what KWATER is.

We must give the essential characteristics of the subject KWATER and omit the irrelevant ones. Without the definition of the object / substance / subject / entity KWATER we cannot have the concept KWATER. This again means that the concept is a definition: nomen est omen. But, the definition is a judgment that determines the content of a concept and the judgment is certainly different from the concept.

Without knowing whether the object of thought exists or does not exist, without knowing the meaning of the word by which we name that object, we cannot know what that object is or have a thought about it. We can have neither vulgarmaterialist nor psychological nor nominalist nor any theory of the concept. 
For now, suffice it to say: the thought of the essence of an object is the definition of that object and the definition is a judgment and is not a concept, i.e. a concept is neither an object nor its definition.

A concept is a simple (undefined) or complex (defined) part of the thought content that has a certain level of logical generality that corresponds on the one hand to the ontological generality of the object and on the other to the linguistic generality of the expression by which the object is denoted.

Thus, as singular or as abstract, as individual or as a general representative of logical generality, the concept is adapted to the special or essential characteristics of the object and the term that the object represents in the expression.

\section{The Concept as a Variable Part of Thought.}

A concept is the cognitive content of a logically ordered structure of a thought in which it has its specific syntactic position (role), degree of logical generality (calculable property), and semantic form (semantic disposition) by which it refers to the object it represents in the thought structure.

Whether a concept is adequately formed and whether the logical structure of thought is adequately constructed depends on whether it adequately represents the ontological structure of the object to which it refers and whether it possesses a semantically adequate referential expression (designation).

A concept is part of a thought, but not every thought has a formal structure of definition! One thought expressed in sentence, for example, "Logic is a philosophical discipline" is not the thought of the essence of logic, but only one part of the thought of the essence of logic, although it already contains three concepts. Also the statement "Aesthetics is a philosophical discipline" or "Ethics is a philosophical discipline". It is a thought expressed on one level of logical generality and with one segment or part of the thought (one segment of the thought content).

Each of these thoughts consists of two concepts, and we want to define the primitive (undefined) part of thought that represents the subject. Only when we list the subject that deals with each of these philosophical disciplines will we get a definition for each of them.

Only when we introduce into the initial definition (differentia specifica) do we get the predicative part of the definition or the function that determines the concept- 
variable ... For example, logic deals with the true, aesthetics with the beautiful and ethics with the good. Therefore, we cannot have the notion of logic, aesthetics or ethics until we have their definition: the closest genus to which they belong and a specific difference (diferentia specifica).

A concept is a structured logical content of an object of thought, i.e. a concept is a part of thought that has a certain level of logical generality marked by a form (one logical structure). It is an integral part of the definition of the essence of things, objects, properties, facts, states of things, or objects of thought and has a different level of logical generality (variability).

We can think about one object of thought in several ways, in one category (logical matrix) differently than in another category, that is, we can determine its essence or quality or quantity or relation or .... But about what we know exists and what it is we have a concept in a different way than about what we don't know exists at all and what it is. We know, for example, what the word WATER means and we have the concept of things / objects / substances WATER. We know from experience that there is a substance marked by that name and we know what the word we denote it means.

The term is a historically (epistemologically) and contextually (pragmatically) variable linguistic and logical representative of the object of thought in statements that can be meaningfully made / formed / expressed about it.

A concept is a part of a whole of thought (part of the whole conceptual content) given in a linguistic expression together with a logical operator for a certain (quantified) degree of logical generality and which stands in relation to a physical object or object of thought possessing one degree of ontological generality.

\section{Calculative Properties of the Concept}

Each concept has its own content that essentially determines it. A concept is a constitutive part of thought, but thought is the distributed content in the concepts from which it is constructed. Conceptual content is part of the whole of thought content, and the whole of thought content is constructed from content that is encompassed and limited by the concepts of which thought is composed.

The fact that the conceptual content of one thought is separated qualitatively and quantitatively from other conceptual contents of the same thought only means that the concept is a very specific sequence of one whole of the conceptual content. 
This further means that each conceptual content has its own quantitative and qualitative definiteness or that it can be determined even when it is represented by a variable, i.e. when it is not known what its "essential characteristic" is and when it remains to be seen what is the meaning or what is the content of the concept.

This quantitative definiteness of a conceptual sequence in the construction of a whole of thought is the scope of a concept that also does not have to be defined and known semantically, but by quantifying that sequence (with a universal or existential quantifier) the area of linguistic content is limited.

The fact that each concept is a part of thought content that has its degree of logical generality and its field of application, its position in the order of parts of thought content, the type of relations it can establish with other parts of thought content, suggests that the concept with its content, scope and range of calculable sequence that has its role in judgment, inference, proof. It should therefore be distinguished

a) the content of the concept ( a part of the structure of conceptual content of the thought)

b) the scope of the concept (intra-conceptual inferential structure, subordinate parts of the concept, subordinate lower concepts under one higher concept, intension of the concept, synthactical property of the concept). Structural properties of the term (intension or the scope of the term). A term has a degree of logical generality that belongs to it from the relationship it acquires ... A term in the logical form in which it appears has its own intensity that determines how far the relation of one term extends and on which subordinate terms that relation depends. The structural properties of a concept show whether it is in a position subordination.

c) the range of the concept (extra-conceptual referential structure, individual thing which are subsumed under concept, reference to the range of individual things fallen under concept, extension of the ceoncept, semantical property of the concept). Semantic properties of the concept. A concept is a part of itraconceptual content of the thought and at the same time a part of extraconceptual referential structure of the thought. A concept in its logical content has its extension which determines its relation to things, or facts, or the states of affaiers to reffere. 
d) the form of categorical use of concept (pragmatic operability of the concept in categorical assertion which is either affirmation or negation. Pragmatic properties of the term. The concept has its way it is applied and its way of using. The pragmatic properties of a concept show its role in affirmation or negation in statements that have a categorical or ascertaining form.

The concept possesses not only the capacity of calculability in formal symbolic logic that applies quantification logic by applying a universal, existential and singular quantifier, but its calculable structure is also open to the application of generalizing quantifiers in the discourse of natural languages and natural deduction. According to Jakkou Väänänenu (2011:283) in every natural language there are a large number of generalizing quantifiers, which differ from the universal quantifier and the particular quantifier in the logical function, e.g.

Two-thirds of citizens voted in favor.

Exactly half of the funds remain for distribution.

Most of the Sarajevo fans wanted to leave the stadium.

Some but not all liked the performance of the composition.

Between $10 \%$ and $20 \%$ of those present were students.

Hardly any of the guests touched the cake.

The number of white balls is even.

There are infinitely many prim numbers.

There are countless many things that are different.

In logic, in the logical calculus, this type of quantifier is closer to temporal, epistemic, situational, ... forms of modal non-classical theories than to the dichotomous two-valued formal logic. Methodologically correctly formulated concept, judgment, conclusion in formal logic must be a clear quantification (granulation or unification) of a variable in logical matrix in order for their content and scope to have calculative properties. 


\section{Conclusion}

We made a difference between syllogistic logic and symbolic logic in the approach to valid logical forms to which the concept belongs.

Syllogistics is a partially formalized logic that does not formalize whole statements but only the constitutive elements of premises and conclusions that represent the concepts of which they are composed as symbols. Therefore syllogistics can be defined as calculus of concepts or calculus of terms. The degree of factual truth of the premise in syllogistic logic determines the type of syllogism (apodictically syllogismos follows from the axiomatic nature of premises, dialectically syllogismos follows from probabilistic nature of premises).

Therefore, the definition of a concept in syllogistic logic is connected with the cognitive-theoretical principles of determining the nature of thought, which is expressed by premises and its correspondence to the facts on which their truth depends. Syllogistic logic is therefore a referential model of logical predication and this is reflected in the understanding of the nature of the concept.

Symbolic logic is fully formalized and axiomatized logic. Its premises expressed by symbols and symbolic formulas have no meaning other than the truth-values assumed to them. The calculation is done with whole statements and not just concepts and what is calculated are the truth-values of the symbols (true or false).

Symbolic logic is an inferential model of logical predication, which has a significant impact on the understanding of the nature of the concept. The concept here should be determined from its calculative logical properties because it is part of the calculative structures of whole statements to which calculus or computation is applied.

The meaning of the concept for its logical use should be determined from its logical or calculative properties that this form of conceptual content possesses.

A concept has an internal logical structure made up of its degree of logical generality, its interactive logical relations as a whole of the conceptual content of a thought, and the logical operations that can be performed on it.

The degree of logical generality determines the position and role of a concept in the sequences of the conceptual content of which the thought is composed (of which the structure of thought is composed) 
The calculative properties of the concept include the logical relations of subordination and subsumption, into which the term can enter according to its degree of logical generality.

A concept is a part of a definition and a part of a thought by which the predicative part of a thought determines the content of the part. A concept is not a definition, so a concept cannot be a thought about the essence of the object to be thought.

That the concept has calculative properties by its logical nature is also shown by the possibility of quantifying the very structure of thought, i.e. the possibility of applying quantifiers by which the term as a variable is more closely defined.

A concept is a cognitive variable or part of a logical matrix in which there are no constants until its meaning is understood (semantically consciousness), that is, until something is defined or what is an object that the term represents in the logical structure of thought.

\section{References}

Anderson, A. R. and Belnap, Jr., Nuel, D. (1990). Entailment. The Logic of Relevance and Necessity. Princeton: Princeton Univ Press.

Tredennick, H. edit. (1997). Aristotle Posterior Analytics. Loeb Classical Library. Cambridge, Massachusetts, London, England: Harvard University Press.

Bennett, B.(2012). Logically Fallacious. The Ultimate Coll. Of Over 300 Logical Fallacies. eBookIt.com.

Boole, G. (1854). An Investigation of the Laws of Thouths, on which are founded the mathematical theories of logic and probabilities. London: Walton and Maberly.

Brandom, R. (2008). Between Saying and Doing: Towards an Analytic Pragmatism. Oxford: Oxford University Press.

Frege, G. (1789, 1964). Begriffsschrift und andere Aufsatze. Hildesheim: Georg Olms.

Frege, G. (auth.), Patzüg, G. (ed.) (1962, 2008 ). Funktion, Begriff, Bedeutung. Fünf logische Studien. Göttingen: Vandenhoeck \& Ruprecht..

Petrović, G. ( 2004). Logika. Zagreb: ŠKZ. 
Porphyrious (auth.), Ibrulj, N. (edit.) (2008). Isagoge. Bilingual: Greek-Basian text. Translated from the ancient Greek original by Nijaz Ibrulj. Sarajevo, Dijalog, 1/ 2008. pp. 1-50.

Putnam H. ( 1973). "Meaning and Reference". The Journal of Philosophy, Vol. 70, No. 19, Seventieth Annual Meeting of the American Philosophical Association Eastern Division. (Nov. 8, 1973), pp. 699-711.

Putnam H. (1975). The Meaning of Meaning, In: Language and Reality. Philosophical Papers 2. London: Cambridge University Press.

Russell, B. (1996). Principles of Mathematics. W. W. Norton \& Company.

Väänänen, J. (2011). Depndence Logic. New approach to independence friendly logic. Cambridge: Cambridge University Press.

Whitehead, A. N., Russell, B. (1927): Principia Mathematica. Volume 1. Cambridge: Cambridge University Press.

Wittgenstein, L (1961, 1974). Tractatus Logico-Philosophicus. London: Routledge. 